\title{
Failed hypospadias in paediatric patients
}

\author{
Marcello Cimador, Santiago Vallasciani, Gianantonio Manzoni, Waifro Rigamonti, Enrico De Grazia \\ and Marco Castagnetti
}

\begin{abstract}
Failed hypospadias refers to any hypospadias repair that leads to complications or causes patient dissatisfaction. The complication rate after hypospadias repairs ranges from $5-70 \%$, but the actual incidence of failed hypospadias is unknown as complications can become apparent many years after surgery and series with lifelong follow-up data do not exist. Moreover, little is known about uncomplicated repairs that fail in terms of patient satisfaction. Risk factors for complications include factors related to the hypospadias (severity of the condition and characteristics of the urethral plate), the patient (age at surgery, endocrine environment, and wound healing impairment), the surgeon (technique selection and surgeon expertise), and the procedure (technical details and postoperative management). The most important factors for preventing complications are surgeon expertise (number of cases treated per year), interposition of a barrier layer between the urethroplasty and the skin, and postoperative urinary drainage. Major complications associated with failed hypospadias include residual curvature, healing complications (preputial dehiscence, glans dehiscence, fistula formation, and urethral breakdown), urethral obstruction (meatal stenosis, urethral stricture, and functional obstruction), urethral diverticula, hairy urethra, and penile skin deficiency.
\end{abstract}

Cimador, M. et al. Nat. Rev. Urol. 10, 657-666 (2013); published online 6 August 2013; doi:10.1038/nrurol.2013.164

\section{Introduction}

Hypospadias is a spectrum disorder. Meatal location and associated ventral curvature are the two major variables that determine the severity of the condition, ranging from patients with a glanular meatus and no associated curvature to those with a perineal meatus and associated curvature of $>90^{\circ} .^{1}$ Preoperative assessment of hypospadias severity is often misleading. The actual starting point of the malformation (where the spongiosum splits into two halves leaving a thin urethra in between) is often much more proximal to the visible hypospadic meatus and its exact location can only be determined after skin degloving. Furthermore, the manoeuvres required for penile straightening can be very different in patients with comparable degrees of curvature and can only be determined intraoperatively using a step-wise approach, going from ventral dissection (with or without dorsal plication) to urethral plate transection (with or without procedures for lengthening the ventral radium of the penis). ${ }^{2}$ Other anatomical characteristics that can influence technique selection and surgical success include the width of the urethral plate, the depth glans, and the overall size of the penis. ${ }^{2}$ In general, when the penis is shorter, ventral lengthening procedures are favoured over dorsal shortening ones, and the patient is more likely to be dissatisfied in the absence of complications.

More than 300 surgical procedures have been described for hypospadias repair, suggesting that no single approach is fully satisfactory for all variants. ${ }^{3}$

Competing interests

The authors declare no competing interests.
Accordingly, reported reoperation rates after primary procedures can exceed $50 \% .{ }^{2}$ Failed hypospadias occurs when the primary surgery does not achieve the cosmetic and functional goals of a straight penis with a glanular meatus that enables normal urinary and sexual function. Failed hypospadias includes all complicated repairs, as well as uncomplicated repairs that do not fulfil patient expectations and cause dissatisfaction. It is worth noting that none of the repairs available to date can be used to create a urethra with the same biological and urodynamic properties as a native urethra and, therefore, functional outcomes, particularly voiding and ejaculatory function, can be severely affected even in the absence of any complications. ${ }^{4}$ Furthermore, patient satisfaction is very subjective and mainly depends on the ability of the patient to cope with cosmetic and functional abnormalities. Patient perception of the outcomes can, therefore, be very subjective and diverge widely from the assessment of the surgeon. For example, the prevalence of persistent curvature after hypospadias repair was significantly lower in patients for whom curvature was assessed by the patient or a parent compared with the surgeon (presumably because these individuals do not give the same relevance to the same degree of curvature), ${ }^{5}$ and adolescents with hypospadias seems to be generally less satisfied with the long-term results of a repair than the paediatric urologists who operated on them as children. ${ }^{6}$

The burden of a failed hypospadias repair can be devastating for a patient and his family. In a series of 1,176 patients with failed hypospadias, a median of five additional procedures (ranging from 2-23) were
Section of Paediatric

Urology and Paediatric Surgery Unit,

Department for Mother and Child Care and Urology, University of Palermo,

Via A. Giordano 3, 90127 Palermo, Italy (M. Cimador,

E. De Grazia).

Paediatric Urology Unit, Ospedale Maggiore-Policlinico, Via Commenda 10, 20122 Milan, Italy (S. Vallasciani,

G. Manzoni). Section of Paediatric Urology, Urology Unit, University Hospital of Padova, Via Giustiniani 2, 35128 Padua, Italy (W. Rigamonti, M. Castagnetti).

Correspondence to: M. Cimador marcello.cimador@ unipa.it 


\section{Key points}

- Hypospadias failure is any repair that leads to complications or causes patient dissatisfaction; the latter is very subjective and difficult to assess

- Surgeon expertise, interposition of barrier layers between the urethroplasty and the skin, and urinary drainage are the most important factors for preventing hypospadias failure

- The most common complications associated with hypospadias failure include residual curvature, fistula formation, urethral breakdown, meatal stenosis, and urethral stricture

- Residual curvature can be addressed by dorsal shortening of the penis; however, urethral substitution should be performed if curvature is caused by a contraction of the ventral neourethra

- Reurethroplasty technique should be selected according to residual curvature secondary to contracture of the neourethra, quality of the residual urethral plate, and suitability of genital skin for elevating flaps

- Urethral dilatation and direct vision internal urethrotomy are much less effective than reurethroplasty for treating urethral strictures after hypospadias repair

\section{Risk factors for failed hypospadias Factors related to the condition}

Several factors can influence the success of hypospadias repair (Box 1). In general, the risk of developing complications increases with the severity of the hypospadias. ${ }^{17}$ The presence of a narrow and shallow urethral plate has also been associated with an increased risk of complications ${ }^{18}$ although this finding has not been confirmed in subsequent studies. ${ }^{19,20}$ Moreover, the assessment of urethral plate characteristics seems to be somewhat subjective, with wide interobserver variability. ${ }^{21}$ It is worth noting that some anatomical characteristics-such as the presence of a short penis, which is relatively common in patients with proximal hypospadias-can cause dissatisfaction in the absence of complications. It can be very difficult to assess the effect of these characteristics on the success of repair. ${ }^{2,22}$

\section{Factors related to the patient}

Age at surgery

Mainly for psychological reasons, hypospadias repair is generally performed when patients are aged about 12 months, although there have been no trials as yet to support this recommendation. ${ }^{23-25}$ Early surgery generally means that the patient is more likely to accept his own body image, thereby improving patient satisfaction, although one group of researchers observed no significant differences in reported rates of satisfaction with penile appearance between patients who received surgery at age $<18$ months compared with age $\geq 18$ months. ${ }^{26}$ Some evidence suggests that performing surgery at a younger age also decreases the risk of complications. In a series of 693 patients, those who underwent repair at age $<12$ months had a $3.4 \%$ complication rate, compared with $18.7 \%$ for patients who received surgery later in life. ${ }^{27}$ Series of patients undergoing delayed hypospadias repair have consistently reported greater complication rates than those generally reported for patients whose surgery is not delayed..$^{28-31}$ However, one research team found no effect of patient age at surgery on urethroplasty complication rates in 669 consecutive prepubertal patients. ${ }^{32}$ Despite these controversies, an age of 6-18 months is generally recommended for surgery. ${ }^{23}$

\section{Hormonal stimulation}

Several studies have shown that preoperative hormonal stimulation facilitates penile growth, irrespective of the administration route. ${ }^{23}$ Hormonal stimulation also reduces the severity of hypospadias, enabling the use of less-complex reconstructive procedures. ${ }^{33}$ However, one research team have reported an increased complication rate in patients receiving hormonal stimulation, suggesting that hormonal stimulation might actually interfere with wound healing. ${ }^{34}$ This hypothesis is supported by in vitro and in vivo studies to show that $\alpha$-dihydrotestosterone inhibits wound closure by inhibiting re-epithelialisation. ${ }^{35}$

\section{Wound healing impairment}

Although many extrinsic and intrinsic factors influence surgical outcomes in hypospadias repair, wound healing 
is probably the most important surgeon-independent factor. Wound-healing processes are strongly influenced by hormones, and sex steroids have contrasting roles in the regulation of cutaneous repair processes. ${ }^{36,37}$ Oestrogens promote wound retraction by enhancing dermal repair processes, inhibiting the production of inflammatory cytokines, promoting re-epithelialization and neoangiogenesis, and increasing the production of platelet-derived growth factors. Androgens, on the other hand, are thought to repress cutaneous repair in both acute and chronic situations, retarding the healing process and increasing inflammation. These effects might explain why some investigators have reported poor outcomes in patients with hypospadias treated with androgen stimulation before urethroplasty. ${ }^{38}$

Furthermore, some studies ${ }^{39}$ have reported an imbalance in the proportion of structural tissue-building epithelial tissue factors (such as cadherin E and claudin 1) to destructive epithelial tissue factors (for example, metalloproteinase 2) in the ventral penile tissue, but not the dorsal penile tissue, of patients with hypospadias. Perhaps this could explain why better results were achieved using the onlay procedure, for which dorsal tissue is transposed ventrally. In this technical repair, the inner dorsal preputial layer is harvested as a flap, preserving the blood supply. The harvested flap is then used to cover the native urethral plate, thus providing the ventral wall of the neourethra.

\section{Factors related to the surgeon \\ Selection of the technique}

Most urologists agree that no single procedure is appropriate for all hypospadias repairs ${ }^{1}$ and several surveys have shown a wide variability in procedure choice among different surgeons. ${ }^{40,41}$ Moreover, many surgeons have modified their surgical approaches as their practice has evolved. ${ }^{27,42}$ Very few studies have provided comparative data for different repairs performed in a uniform setting. ${ }^{43}$ Although some techniques have been associated with some specific complications-for example, urethral diverticula occurs almost exclusively after flap tube repairs ${ }^{44}-$ a systematic review of the literature on the treatment of primary severe hypospadias concluded that no single urethroplasty technique is clearly superior to the others. ${ }^{2}$

\section{Surgeon expertise}

In a recent 'round table' meeting of experts on hypospadias, it was suggested that intellectual interest in the condition and number of operated cases are the two most important surgeon-dependent variables for predicting the success of hypospadias repair. ${ }^{22}$ In a series of 299 patients undergoing primary hypospadias correction, complication rates improved considerably as the surgeon became more experienced. ${ }^{45} \mathrm{~A}$ cut-off threshold of 100 cases per year has been proposed for classifying surgeons as experts in hypospadias surgery, ${ }^{22}$ although one team has suggested that this threshold should be lowered to 50 cases per year, as risk for hospital readmission within the 12 months after primary repair was found to be lower in centres treating more than 50 cases per year compared with those performing fewer procedures. ${ }^{46}$
Box 1 | Factors influencing results in hypospadias repair

Factors related to the patient

- Endocrine environment

- Wound-healing impairment

- Decreased growth factor activity

Factors related to the surgeon

- Expertise

- Choice of procedure

- Perioperative and postoperative management

Factors related to the diagnosis

- Incorrect identification of the urethral ending

- Incorrect evaluation of the urethral plate

- Incorrect evaluation of the spongiosum

Factors related to the procedure

- Inadequate technique

- Inadequate choice of repair

- Influence of suture materials

- Urethral stenting

\section{Factors related to the procedure}

\section{Technical details}

Technical details are key to the success of hypospadias surgery. Coverage of the urethroplasty with multiple layers of well-vascularized tissue is particularly important for both distal and proximal hypospadias. ${ }^{47-49}$ The flaps most commonly used for uethroplasty coverage include flaps of subcutaneous dartos elevated from around the urethral plate, the prepucial pedicle transposed ventrally, and the tunica vaginalis flap. The importance of suture materials is unclear. Suture materials with a longer reabsorption time might favour healing and prevent fistula formation, but they might also cause prolonged tissue reaction, potentially increasing the risk of stricture formation in the reconstructed urethra. Some studies have indicated a key role in repair success, ${ }^{50,51}$ whereas others have shown no difference in urethral complication rates when using different suture materials. ${ }^{52,53}$

\section{Postoperative management}

In one study, early mobilization (within $48 \mathrm{~h}$ postoperatively) was shown to decrease the incidence of fistulas from $22 \%$ to $9.8 \%$, whereas factors such as catheter dislodgement and blockage, presence of postoperative erections, constipation-related straining, and interference with dressings were associated with increased complication rates. ${ }^{54}$ However, type and duration of urinary diversion, type of dressing, catheter size, and anaesthetic regime have been shown not to significantly influence outcomes ${ }^{55}$ and a recent review of the literature on perioperative management of primary severe hypospadias concluded that most interventions, such as postoperative antibiotic prophylaxis or wound dressing, ${ }^{56-58}$ are based on weak evidence and their influence on repair outcomes is poorly defined. ${ }^{23}$ Only postoperative urinary drainage has been consistently shown to be a critical factor in reducing the complication rate. ${ }^{59}$

\section{Management of complications}

Failed hypospadias is not only a urethral issue; the corporeal bodies and penile skin are also commonly 
Table 1 | Overview of complications in hypospadias failure

\begin{tabular}{|c|c|c|c|c|}
\hline Complication & Prevalence & Clinical presentation & Diagnostic tools & $\begin{array}{l}\text { Treatment options } \\
\text { (success rate) }\end{array}$ \\
\hline Recurrent curvature & $9-32 \%^{5}$ & $\begin{array}{l}\text { Curved penis } \\
\text { during erection }\end{array}$ & $\begin{array}{l}\text { Clinical assessment; photos; } \\
\text { erection test }\end{array}$ & $\begin{array}{l}\text { No treatment if }<30^{\circ}(\mathrm{NR}) \text {; } \\
\text { corporoplasty }\left(93-96 \%^{16,60}\right) \text {; } \\
\text { urethral substitution }(\mathrm{NR})\end{array}$ \\
\hline $\begin{array}{l}\text { Preputial } \\
\text { dehiscence or } \\
\text { secondary phimosis }\end{array}$ & $2-20 \% 68$ & Tight or open prepuce & Clinical assessment & Circumcision $\left(100 \%{ }^{66}\right)$ \\
\hline Glans dehiscence & $0-8 \%{ }^{69}$ & $\begin{array}{l}\text { Meatal regression } \\
\text { to coronal sulcus }\end{array}$ & Clinical assessment & $\begin{array}{l}\text { No treatment (NR); redo distal } \\
\text { urethroplasty }\left(70-95 \% \%^{69-71}\right)\end{array}$ \\
\hline Urethral fistula & $4-28 \%^{72}$ & Double stream & $\begin{array}{l}\text { Clinical assessment } \\
\text { (number, size, and location); } \\
\text { calibration of distal urethra }\end{array}$ & $\begin{array}{l}\text { Simple closure }\left(75-100 \%^{74-74}\right) \\
\text { closure with flaps }\left(90-100 \%^{73-74}\right)\end{array}$ \\
\hline Urethral breakdown & NR & Recurrent hypospadias & Clinical assessment & $\begin{array}{l}\text { Retubularization }\left(74-81 \%^{76,77}\right) \text {; } \\
\text { augmentation urethroplasty } \\
\left(76-85 \%^{76,93)} \text {; substitution }\right. \\
\text { urethroplasty }\left(62-66 \%^{76,81}\right)\end{array}$ \\
\hline Meatal stenosis & $0-14 \%^{87}$ & $\begin{array}{l}\text { Weak stream; } \\
\text { other lower urinary } \\
\text { tract symptoms }\end{array}$ & $\begin{array}{l}\text { Clinical assessment; } \\
\text { meatal calibration; retrograde } \\
\text { and voiding urethrography and } \\
\text { cystoscopy if stricture suspected }\end{array}$ & Meatotomy $\left(100 \%{ }^{87}\right)$ \\
\hline Urethral stricture & $6-12 \%^{88}$ & $\begin{array}{l}\text { Weak stream; } \\
\text { other lower urinary } \\
\text { tract symptoms }\end{array}$ & $\begin{array}{l}\text { Clinical assessment; urethral } \\
\text { calibration; retrograde and } \\
\text { voiding urethrography and } \\
\text { cystoscopy if stricture suspected }\end{array}$ & $\begin{array}{l}\text { Urethral dilatation }\left(21-40 \%^{88}\right) \text {; } \\
\text { endoscopic incision (NR); } \\
\text { augmentation urethroplasty } \\
\left(53-100 \% \%^{88}\right) \text {; substitution } \\
\text { urethroplasty (NR) }\end{array}$ \\
\hline $\begin{array}{l}\text { Urethral stricture } \\
\text { owing to BXO* }\end{array}$ & $4-16 \%^{97,98}$ & $\begin{array}{l}\text { Weak stream; } \\
\text { other lower urinary } \\
\text { tract symptoms }\end{array}$ & $\begin{array}{l}\text { Clinical assessment; urethral } \\
\text { calibration; retrograde and } \\
\text { voiding urethrography and } \\
\text { cystoscopy if stricture suspected }\end{array}$ & $\begin{array}{l}\text { Substitution urethroplasty with } \\
\text { oral mucosa graft (NR) }\end{array}$ \\
\hline $\begin{array}{l}\text { Urethral } \\
\text { diverticulum } \ddagger\end{array}$ & $4-12 \%^{44}$ & $\begin{array}{l}\text { Urethral ballooning } \\
\text { during micturition }\end{array}$ & $\begin{array}{l}\text { Clinical assessment; calibration } \\
\text { of distal urethra; retrograde and } \\
\text { voiding urethrography }\end{array}$ & Urethral tapering $\left(100 \%^{44}\right)$ \\
\hline Hairy urethra & $5-15 \%^{105}$ & $\begin{array}{l}\text { Recurrent urinary } \\
\text { infections and } \\
\text { urethral stones }\end{array}$ & Urethroscopy & $\begin{array}{l}\text { Ablation of hairs and their } \\
\text { follicles (NR); substitution } \\
\text { urethroplasty (NR) }\end{array}$ \\
\hline $\begin{array}{l}\text { Abnormal skin } \\
\text { configuration }\end{array}$ & $55 \%{ }^{60}$ & Abnormal appearance & Clinical assessment & Skin reconfiguration (NR) \\
\hline Skin deficiency & $5 \%^{107}$ & Trapped penis & Clinical assessment & $\begin{array}{l}\text { Free skin grafts (NR); } \\
\text { skin expanders (NR) }\end{array}$ \\
\hline
\end{tabular}

involved. The most common complications include recurrent curvature, preputial dehiscence, glans dehiscence, urethral fistula or breakdown, meatal or urethral stenosis, urethral stricture, urethral diverticulum, hairy urethra, penile skin deficiency, and abnormal penile skin configuration (Table 1 ). In a series of 50 adults with failed hypospadias, urethral strictures $(n=36)$, urethrocutaneous fistulas $(n=12)$, persistent hypospadias $(n=7)$, hair in the urethra $(n=6)$, and severe penile curvature $(n=7)$ were observed. ${ }^{8}$ Complications were rarely isolated. In a large series of failed hypospadias repairs, half of all patients undergoing urethral reconstruction also required complex procedures to resurface the penile shaft or reconfigure the whole genitalia. ${ }^{60}$ When combined with urethral breakdown or stricture, scarring and retraction of the neourethra are likely to lead to recurrent curvature. The term 'hypospadias cripple' is used to describe a scarred hypovascular and shortened penis caused by multiple failed attempts at hypospadias repair
(Figure 1) ${ }^{61}$ Incorporation of additional extragenital tissue is often necessary for repair in these patients.

\section{Residual and recurrent curvature}

Curvature can persist after a primary repair (owing to inappropriate correction during initial surgery) or recur if previous manoeuvres or attempts at ventral tethering have failed, leading to retraction of the reconstructed urethra or the penile skin. No longitudinal cohort studies have been set up to determine the prevalence of curvature persistence or recurrence in relation to the initial straightening manoeuvres. In a study of 100 patients with proximal hypospadias and severe curvature, recurrent curvature was reported in a total of 22 patients, including three (of 32) children who underwent ventral lengthening procedures and 19 (of 68) who underwent dorsal plication $(9 \%$ versus $28 \%$; $P=0.03) .{ }^{6}$ This study suggests that ventral lengthening could be more effective and durable in achieving penile straightening. However, in another 

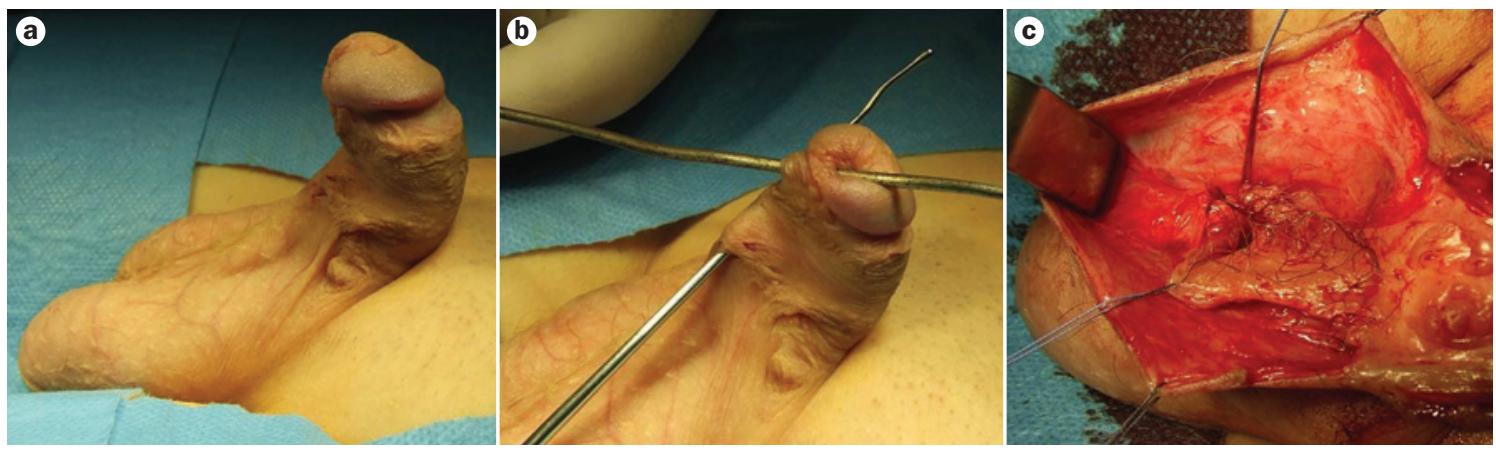

Figure 1 | A case of hypospadias cripple in a 19-year-old boy; the term is used to describe a scarred hypovascular and shortened penis caused by multiple failed attempts at hypospadias repair. a | Persistent curvature during spontaneous erection associated with skin scarring. $\mathbf{b} \mid$ Metallic probes show the presence of multiple urethral fistulas. $\mathbf{c} \mid$ Hairs are detected inside the lumen of the scrotal urethra after opening.

study of 22 patients with recurrent curvature $>10$ years after initial penile straightening, 19 patients had received dorsal plication as their initial procedure and three had undergone ventral tunica vaginalis grafting. ${ }^{16}$ Median age at onset of recurrence was 16 years (ranging from 12-18 years). These data show that penile curvature can recur after both dorsal plication and ventral procedures, and that most recurrences occur during puberty.

Diagnosing residual curvature is not always easy, owing to the lack of a standardized diagnostic tool for defining the degree of residual curvature that should be considered clinically relevant. The surgeon often has to rely on patient or parental report, which can vary significantly from surgeon assessment. ${ }^{6}$ If physical examination during erection is unrealistic, photographs should be taken by the patient during erection. In any case, if the correction of residual or recurrent curvature is elected, an intraoperative erection test is mandatory before embarking on any further procedure. Treatment of residual or recurrent curvature should follow the same principles as for primary curvature. ${ }^{2}$ Minor residual curvature $\left(<30^{\circ}\right)$ can be left untreated provided it does not interfere with sexual activity. If treatment is required, options include dorsal shortening procedures or ventral lengthening, which can sometimes require the removal of all ventral scarred tissue and urethral substitution. The former is potentially easier, but ventral lengthening should be considered when the curvature is caused by a shortage of skin or a contraction of the neourethra.

\section{Inappropriate healing}

Preputial dehiscence and secondary phimosis

Preputial reconstruction is often requested by parents, particularly in European countries with large numbers of uncircumcised males. Moreover, the foreskin is erogenous tissue that could be important for the future sexual life of the patient. ${ }^{62-64}$ Unfortunately, preputial reconstruction increases the risk of postoperative morbidity and, therefore, of repair failure. Specific complications include foreskin dehiscence and secondary phimosis. In one study, total dehiscence and phimosis were reported in $6 \%$ and $12.6 \%$ of patients treated with preputioplasty for hypospadias repair. ${ }^{65}$ We have reported rates of $3.8 \%$ for dehiscence and $6.3 \%$ for secondary phimosis in patients who underwent distal hypospadias surgery. After a mean follow-up duration of 3.7 years, $90 \%$ of patients had retractable foreskins. ${ }^{66,67}$ Although the relevance of cosmetic appearance following preputial reconstruction remains controversial, ${ }^{68}$ cosmetic appearance was considered to be 'good' (according to surgeon assessment) for all of our uncomplicated patients and none of the parents of these patients reported dissatisfaction. ${ }^{66}$ Overall, preputial reconstruction can be performed safely and with a low complication rate in appropriately selected patients. ${ }^{68}$

\section{Glans dehiscence}

Prevalence of glans dehiscence ranges from $0-8 \%$. In the only specific study of this complication, risk of dehiscence was not affected by age at surgery, preoperative testosterone use, or glansplasty suture. However, the risk of glans dehiscence after tabularised incised plate repair was 3.6-fold greater in patients with proximal hypospadias compared with distal meatal hypospadias and 4.7 -fold greater for repeat procedures (14\%) than for primary repairs ( $4 \%) .{ }^{69}$ Most patients are treated conservatively for glans dehiscence. Indeed, although a coronal regression of the meatus is likely to have a negative effect on cosmetic appearance, this complication might actually improve urinary function, as it reduces outflow resistance and, therefore, the risk of urinary obstruction. Indications for the correction of glans dehiscence are similar to those for extremely distal hypospadias, namely spraying, deviation of urinary stream, and unsightly glans appearance. ${ }^{70}$ Several techniques can be used for repeat reconstruction of the distal urethra, including the well-established meatal-based flipped flap approach. ${ }^{71}$

\section{Fistula formation}

Reportedly, fistula formation occurs in $4-28 \%$ of patients after hypospadias repair, ${ }^{72}$ either in isolation or in association with a meatal or urethral stenosis. The presence of stenosis should always be ruled out before embarking on fistula closure. Treatment depends on the number, location, and size of the fistulas. Prolonged catheterization might be suitable for treating small fistulas that occur soon after the repair, whereas formal surgical repair is 
Failed hypospadias: urethral breakdown

Curvature greater than $30^{\circ}$ or interfering with sexual activity

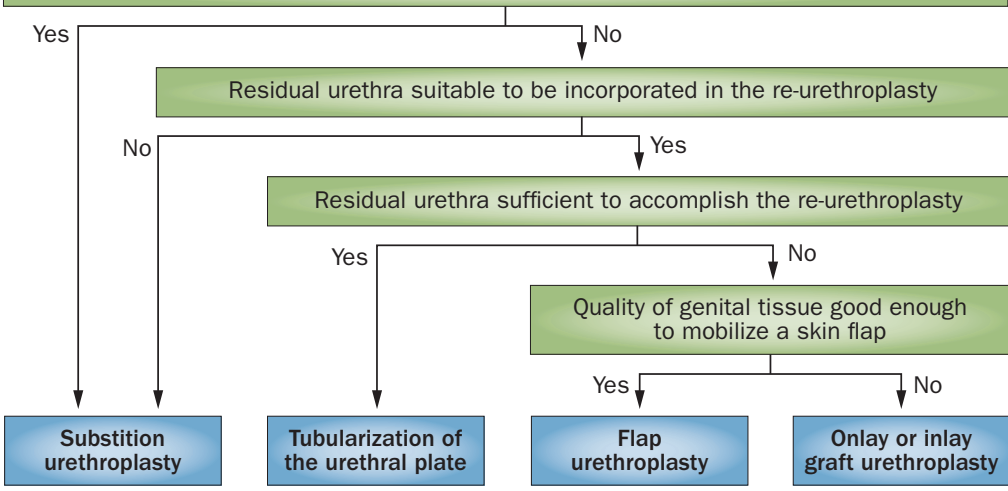

Figure 2 | Algorithm for the management of failed hypospadias owing to urethral breakdown.

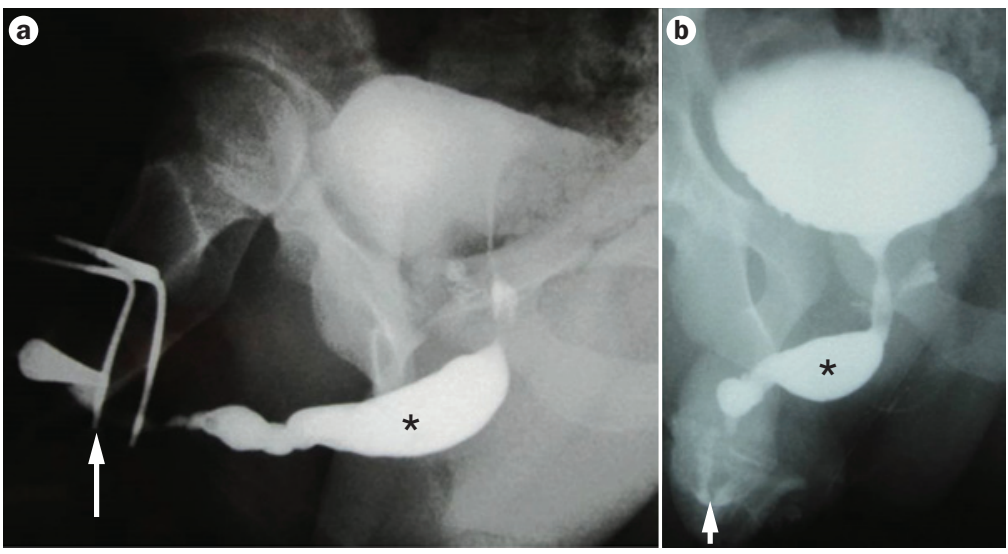

Figure 3 Retrograde and voiding urethrographies in a patient with urethral stricture following hypospadias repair. a | During retrograde injection of contrast from the glanular urethral meatus (denoted by an arrow), a narrow urethral segment is visible. This segment, which is proximal to the stenosis, is dilated (denoted by an asterisk). b | During voiding, the dilated segment becomes even more apparent (denoted by an asterisk). No contrast is visible between the dilated urethral segment and the tip of the penis (denoted by an arrow).

required for those that persist for $>6$ months after the initial hypospadias surgery. The repair can be simple or with flaps. Although simple repairs are easier, they are also less effective and, therefore, generally less appropriate for large and recurrent fistulas. ${ }^{72-74}$ Redo distal urethroplasty might be more effective than fistula repair for fistulas that arise at, or distally to, the coronal sulcus. Urethral mobilization and advancement might also be considered for treating persistently recurrent hypospadias fistulas. ${ }^{75}$

\section{Urethral breakdown}

Treatment for urethral dehiscence will depend on the length and extension of the neourethral defect, the amount of scar tissue encountered, and the availability of local skin. ${ }^{76}$ Thus, in order to select the appropriate repair option, the surgeon should check for persistent ventral curvature (and gauge whether this is secondary to contracture of the neourethra constructed during the previous surgery) and assess the suitability of the residual urethral plate for reuse and the genital skin for mobilization and incorporation in the new repair procedure (Figure 2). When a suitable urethral plate is available, possible strategies include tubularization of the plate (with or without a midline-releasing incision), tubularization of the urethral plate after inlay grafting of the dorsal midline incision, and placement of a flap or graft onlay over the urethral plate. ${ }^{76-78}$

When the plate is visibly scarred or deemed to contribute significantly to the persistence of ventral curvature, urethral substitution is required, typically involving preputial island tube placement or staged-graft urethroplasty. ${ }^{76,78}$ If extragenital tissue is to be used as graft owing to paucity of local tissue, most surgeons prefer to use an oral mucosa graft harvested from the lower lip or inner cheek. ${ }^{79-81}$ The tongue and the retroauricular region are additional potential harvesting sites. ${ }^{82,83}$ No graft is definitively superior to the others in terms of harvesting site morbidity or success of the urethroplasty. ${ }^{84,85}$ Irrespective of the graft used, the first stage of repair involves quilting the graft onto the ventral aspect of the penile shaft after the removal of any scarred tissue. The graft is then tabularised around 6 months later. This staged approach to repair enables the graft to 'take' properly before tabularization, which minimizes the risk of postoperative complications. ${ }^{86}$

\section{Urethral obstruction}

\section{Meatal stenosis}

Major causes of obstructed voiding after hypospadias repair include meatal stenosis and urethral stricture. Meatal stenosis is particularly common with repair techniques such as tabularized preputial flap urethroplasty (performed when the glans is tunnelled) and tubularized incised plate urethroplasty. The latter technique-which is one of the most commonly performed repairs-is associated with a $0-14 \%$ risk of meatal stenosis, usually occurring within 6 months of the procedure. ${ }^{87} \mathrm{~A}$ deep incision of the plate and the creation of a wide meatus minimize the risk of this complication and negate the need for calibration of the neourethra. ${ }^{87}$ The most common presenting symptoms are a weak stream, a long and thin stream, and spraying. Clinical diagnosis is generally based on meatal calibration; radiological investigations are unnecessary unless proximal extension of the stricture is suspected. Treatment is relatively straightforward and entails a ventral cutback of the external urethral meatus, namely a ventral meatotomy.

\section{Urethral stricture}

The reported prevalence of urethral strictures proximal to the meatus after hypospadias repair is $6-12 \%,{ }^{88}$ and hypospadias surgery is the major cause of urethral stricture formation in adults aged $<45$ years. ${ }^{89}$ Patients with strictures most commonly present with a weak stream, with or without lower urinary tract symptoms. A dilatation of the urethra proximal to the stricture can be observed upon physical examination. Retrograde and voiding cystourethrography (Figure 3 ) and cystoscopy are used to diagnose urethral strictures, as well as determine the location, degree, and extension of the stricture. 
It is worth noting that obstructive voiding can occur after hypospadias surgery in the absence of a true stricture, owing to functional obstruction caused by a stiff reconstructed urethral segment. ${ }^{90}$

Treatment modalities include urethral dilatation, direct vision internal urethrotomy (DVIU), and reurethroplasty. Dilatation and DVIU are less-invasive approaches than reurethroplasty and are almost always considered as primary approaches. However, success rates for these techniques are quite low, ranging from $21-40 \%,{ }^{88}$ and are not generally improved by a 3 -month period of clean intermittent catheterization postoperatively. ${ }^{88,91}$ In addition, the chance of a successful DVIU decreases with each repeated attempt, and possibly exposes to the risk of stricture lengthening. ${ }^{88,91}$ The available evidence suggests that it is only worth attempting dilatation or DVIU for the repair of failed hypospadias with relatively short $(1-1.5 \mathrm{~cm})$ urethral strictures.

For longer strictures, or if the first attempt at repair fails, redo urethroplasty should be considered. Alternative treatments for these patients include single-stage augmentation urethroplasty or staged urethral substitution. The former technique involves widening the narrow urethral segment via the incorporation of a flap (if local skin is available) or a graft of extragenital tissue. The graft can be placed above the open narrowed urethral segment (onlay graft) or dorsally (inlay graft); ${ }^{92-94}$ there is no evidence that one graft orientation is superior to the other. Indeed, the most important step for success seems to be coverage of the flap with well-vascularized tissue. ${ }^{94}$ During substitution urethroplasty, all of the scarred tissue is excised and substituted for an extragenital graft. Under these circumstances, a staged approach is generally favoured. ${ }^{95}$ Importantly, all patients with urethral strictures should be carefully assessed for evidence of balanitis xerotica obliterans (BXO) before treatment. ${ }^{96} \mathrm{BXO}$ is thought to account for $4-15 \%$ of the strictures that occur after hypospadias repairs in which the urethroplasty is performed using a prepucial flap or graft. ${ }^{97,98}$ Substitution urethroplasty with oral mucosa is mandatory in the presence of BXO. ${ }^{98,99}$

\section{Urethral diverticula}

Dilation of the neourethra (Figure 4), also known as megalourethra, has been described after the correction of proximal hypospadias, ${ }^{100,101}$ although only for flap tube repairs. ${ }^{44}$ It is unclear whether this complication is caused by an intrinsic lack of flap strength or by a subclinical or functional distal obstruction. Tapering of the affected segment with excessive de-epithelialisation of the urethral wall and reinforcement of the reduced neourethra by pseudospongioplasty is generally effective.

\section{Hairy urethra}

In order to minimize the risk of hairy urethra formation, hair-bearing tissue should not be used in the repair of hypospadias. This practice has been recognized for some time and hairy urethra are generally only observed today in patients who were operated on many years ago using techniques that have since been abandoned. The most common presenting symptoms for this condition-which

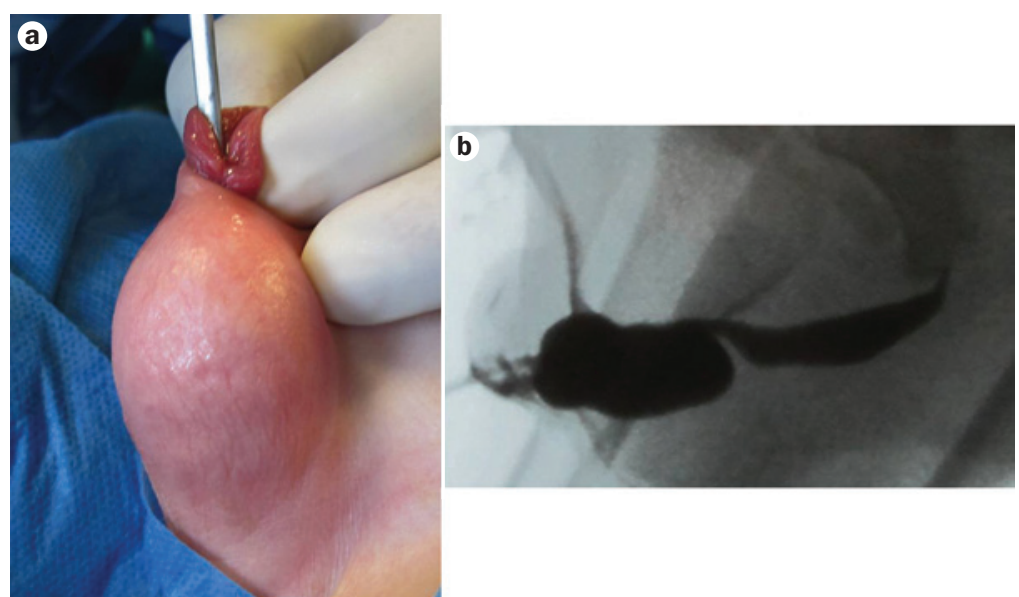

Figure 4 | A case of megalourethra. a | Massive dilatation of the reconstructed penile urethra. b | Retrograde urethrograph showing an abnormal dilatation of the reconstructed urethral segment owing to the abnormal dictation of the preputial flap, which is not supported by the spongiosum used for the urethroplasty.

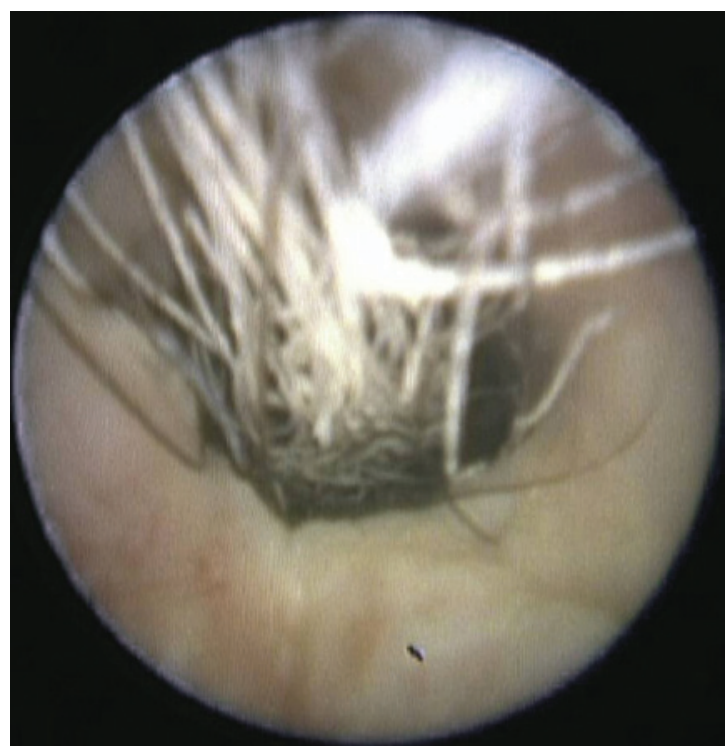

Figure 5 | Endoscopic view of a hairy urethra in a 16-yearold boy presenting with recurrent episodes of UTI and urethral bleeding.

is diagnosed by cystoscopy - are recurrent urinary infections and stone formation within the urethra (Figure 5). Treatment is almost always required. Simple grasper extraction of the hairs is seldom effective, as it does not ensure removal of the hair follicle, thereby preventing regrowth. Thus, alternative treatments include carbon dioxide laser desiccation, neodymium-doped yttriumaluminium-garnet (Nd:YAG) laser photocoagulation, electrolysis treatment, and hair tricholysis with thioglycolate. ${ }^{102-105}$ Endoscopic urethrolithotripsy is recommended as the initial treatment, followed by periodic self-catheterization of the neourethra to prevent the formation of hairballs. ${ }^{106}$ If these treatments fail, open surgical revision-which entails a substitution urethroplasty of the hair-bearing segment with a free graft of extragenital tissue-can be used as a last resource. 


\section{Skin complications}

Penile skin coverage is one of the most neglected steps of primary hypospadias repair. More than half of all hypospadias reoperations require a rearrangement of the penile skin. ${ }^{60}$ In the majority of patients, the redistribution of available skin suffices, although this approach often requires creativity and ad hoc solutions. However, multiple penile surgeries can substantially reduce the amount of penile skin that is available for redistribution and, sometimes, the available penile skin is inadequate for a straight erection (also known as trapped penis). Fortunately, this problem occurs relatively infrequently, affecting $<5 \%$ of hypospadias cripple repairs. ${ }^{107}$ Under these circumstances, two main strategies can be used-penile coverage with free skin grafts or a staged reconstruction with delayed penile resurfacing after skin expanders have been inserted to increase the amount of available skin. Free skin grafts are easy to harvest, although major drawbacks include possible secondary contraction, different pigmentation from genital skin, and loss of sensation. ${ }^{108}$ Tissue expanders, on the other hand, enable penile resurfacing with genital tissue. Nevertheless, tissue expansion is a lengthy process (taking more than a year in some cases), can be slightly uncomfortable for the patient, creates an unnatural distortion of the dorsum of the penis, requires multiple office visits and inflations, and has psychological implications. ${ }^{107}$ Also, these tissue expanders occasionally need to be removed owing to extrusion or infection.

\section{Conclusions}

A consensus on the standardized assessment of hypospadias surgery has not yet been reached. In general, failed hypospadias refers to any repair that leads to complications or causes patient dissatisfaction. However, patient satisfaction is very subjective and many complications only become evident after many years of follow-up assessment, highlighting the need for life-long followup data, which are not yet available. Complication rates, ranging from $5-70 \%$, increase linearly with severity of the condition, although the role of other anatomical characteristics is unclear. Likewise, it is unclear whether age at surgery or preoperative hormonal stimulation influence surgical outcomes. Surgeon expertise, defined as intellectual interest in the condition and number of cases treated per year, is a key factor in the prevention of failed hypospadias, irrespective of the technique used. Interposition of a barrier layer (between the urethroplasty and the skin) and postoperative urinary drainage are the two most important technical considerations for preventing complications following hypospadias repair.

The most common major complications that lead to failed hypospadias are recurrent curvature, preputial dehiscence, glans dehiscence, urethral fistula or breakdown, meatal or urethral stenosis, urethral stricture, urethral diverticulum, hairy urethra, penile skin deficiency, and abnormal penile skin configuration (Table 1). Residual curvature can be addressed by dorsal shortening of the penis, unless caused by a contraction of the ventral neourethra (in which case, urethral substitution should be favoured). For patients with complete urethral breakdown, the surgeon should assess whether residual curvature is secondary to contracture of the neourethra before embarking on a reurethroplasty. They should also consider the suitability of the residual urethral plate to be reused and the suitability of genital skin for elevating urethral flaps. Urethral dilatation and direct vision internal urethrotomy are easier options than redo urethroplasty for treating urethral stricture, but are also much less effective. Irrespective of the complications leading to the failure of the primary repair, paucity of residual local tissue seems to be the greatest challenge for further surgery. As such, there is much interest in the development of tissue engineering techniques that can generate large amounts of tissue with appropriate and specific biological characteristics.

\section{Review criteria}

Data for this Review were selected by searching the Medline database for the keywords "hypospadias", "failure", "complications", and "reoperation". English-language articles were selected on the basis of relevance. Key studies related to failed hypospadias that were already known to the authors were also included.
1. Baskin, L. S. \& Ebber, M. B. Hypospadias: anatomy, etiology, and technique. J. Pediatr. Surg. 41, 463-472 (2006).

2. Castagnetti, M. \& El-Ghoneimi, A. Surgical management of primary severe hypospadias in children: systematic 20-year review. J. Urol. 184, 1469-1474 (2010).

3. Smith, E. D. The history of hypospadias. Pediatr. Surg. Int. 12, 81-85 (1997).

4. Rynja, S. P., de Jong, T. P., Bosch, J. L. \& de Kort, L. M. Functional, cosmetic and psychosexual results in adult men who underwent hypospadias correction in childhood. J. Pediatr. Urol. 7, 504-515 (2011).

5. Braga, L. H. et al. Ventral penile lengthening versus dorsal plication for severe ventral curvature in children with proximal hypospadias. J. Urol. 180, 1743-1747 (2008).

6. Mureau, M. A., Slijper, F. M., Slob, A. K., Verhulst, F. C. \& Nijman, R. J. Satisfaction with penile appearance after hypospadias surgery: the patient and surgeon view. J. Urol. 155, 703-706 (1996).

7. Barbagli, G., Perovic, S., Djinovic, R., Sansalone, S. \& Lazzeri, M. Retrospective descriptive analysis of 1,176 patients with failed hypospadias repair. J. Urol. 183, 207-211 (2010).

8. Myers, J. B., McAninch, J. W., Erickson, B. A. \& Breyer, B. N. Treatment of adults with complications from previous hypospadias surgery. J. Urol. 188, 459-463 (2012).

9. Prasad, M. M., Marks, A., Vasquez, E., Yerkes, E. B. \& Cheng, E. Y. Published surgical success rates in pediatric urology-fact or fiction? J. Urol. 188, 1643-1648 (2012).

10. Snodgrass, W. T., Bush, N. \& Cost, N. Tubularized incised plate hypospadias repair for distal hypospadias. J. Pediatr. Urol. 6, 408-413 (2010).
11. Shukla, A. R., Patel, R. P. \& Canning, D. A The 2-stage hypospadias repair. Is it a misnomer? J. Urol. 172, 1714-1716 (2004).

12. Hinder, U. T., Duran, F. R. \& Caravaca, M. P. in Long term results in plastic and reconstructive surgery $1^{\text {st }}$ edn Vol. 1 (ed. Goldwyn, R. M.; Boston Little Brown \& Co., USA, 1980).

13. Spinoit, A. F., Poelaert, F., Groen, L. A., Van Laecke, E. \& Hoebeke, P. Hypospadias repair in a single reference centre: Long term follow-up is mandatory to detect the real complication rate! J. Urol. http://dx.doi.org/ 10.1016/j.juro.2012.12.100.

14. Wood, H. M., Kay, R., Angermeier, K. W. \& Ross, J. H. Timing of the presentation of urethrocutaneous fistulas after hypospadias repair in pediatric patients. J. Urol. 180, 1753-1756 (2008). 
15. Nuininga, J. E., De Gier, R. P. E., Verschuren, R. \& Feitz, W. F. J. Long-term outcome of different types of 1-stage hypospadias repair. J. Urol. 174 1544-1548 (2005).

16. Vandersteen, D. R. \& Husmann, D. A. Late onset recurrent penile chordee after successful correction at hypospadias repair. J. Urol. 160, 1131-1133 (1998).

17. Sarhan, O. M. et al. Factors affecting outcome of tubularized incised plate (TIP) urethroplasty: single center experience with 500 cases. J. Pediatr. Urol. 5, 378-382 (2009).

18. Holland, A. J. \& Smith, G. H. Effect of the depth and width of the urethral plate on tubularized incised plate urethroplasty. J. Urol. 164, 489-491 (2000).

19. Nguyen, M. T., Snodgrass, W. T. \& Zaontz, M. R. Effect of urethral plate characteristics on tubularized incised plate urethroplasty. J. Urol. 171, 1260-1262 (2004)

20. Sarhan, O., Saad, M., Helmy, T. \& Hafez, A. Effect of suturing technique and urethral plate characteristics on complication rate following hypospadias repair: a prospective randomized study. J. Urol. 182, 682-685 (2009).

21. El-Hout, Y. et al. Assessment of urethral plate appearance through digital photography: do pediatric urologists agree in their visual impressions of the urethral plate in children with hypospadias? J. Pediatr. Urol. 6, 294-300 (2010)

22. Snodgrass, W., Macedo, A., Hoebeke, P. \& Mouriquand, P. D. Hypospadias dilemmas: a round table. J. Pediatr. Urol. 7, 145-157 (2011).

23. Castagnetti, M. \& El-Ghoneimi, A. The influence of perioperative factors on primary severe hypospadias repair. Nat. Rev. Urol. 8, 198-206 (2011).

24. American Academy of Pediatrics. Section on Urology. Action committee for determining timing of elective surgery on the genitalia of male children. Timing of elective surgery on the genitalia of male children with particular reference to the risks, benefits and psychological effects of surgery and anesthesia. American Academy of Pediatrics. Pediatrics 97, 590-594 (1996).

25. Jones, B. C., O’Brien, M., Chase, J., Southwell, B. R. \& Hutson, J. M. Early hypospadias surgery may lead to better psychosexual outcome. J. Urol. 182, 1744-1750 (2009).

26. Weber, D. M., Schonbucher, V. B., Gobet, R. Gerber, A. \& Landot, M. A. Is there an ideal age for hypospadias repair? A pilot study. J. Pediatr. Urol. 5, 345-350 (2009).

27. Marrocco, G., Vallasciani, S., Fiocca, G. \& Calisti, A. Hypospadias surgery: a 10-year review. Pediatr. Surg. Int. 20, 200-203 (2004).

28. Ziada, A. et al. Outcomes of hypospadias repair in older children: a prospective study. J. Urol. 185, 2483-2486 (2011).

29. Dodson, J. L., Baird, A. D., Baker, L. A., Docimo, S. G. \& Mathews, R. I. Outcomes of delayed hypospadias repair: implications for decision making. J. Urol. 178, 278-281 (2007).

30. Kocherov, S. et al. Outcome of hypospadias repair in toilet-trained children and adolescents. Pediatr. Surg. Int. 28, 429-433 (2012).

31. Eassa, W., Jednak, R., Capolicchio, J. P. Brzezinski, A. \& El-Sherbiny, M. Risk factors for re-operation following tubularized incised plate urethroplasty: a comprehensive analysis. Urology 77, 716-720 (2011).

32. Bush, N. C., Holzer, M., Zhang, S. \& Snodgrass, W. Age does not impact risk for urethroplasty complications after tubularized incised plate repair of hypospadias in prepubertal boys. J. Pediatr. Urol. 9, 252-256 (2013).
33. Koff, S. A. \& Jayanthi, V. R. Preoperative treatment with human chorionic gonadotropin in infancy decreases the severity of proximal hypospadias and chordee. J. Urol. 162, 1435-1439 (1999).

34. Gorduza, D. B. et al. Does androgen stimulation prior to hypospadias surgery increase the rate of healing complications? A preliminary report. J. Pediatr. Urol. 7, 158-161 (2011).

35. Gilliver, S. C. et al. 5a-dihydrotestosterone (DHT) retards wound closure by inhibiting reepithelialization. J. Pathol. 217, 73-82 (2009).

36. Gilliver, S. C. et al. The hormonal regulation of cutaneous wound healing. Clin. Dermatol. 25, 56-62 (2007)

37. Gilliver, S. C. et al. Sex steroids and cutaneous wound healing: the contrasting influences of estrogens and androgens. Climacteric 10, 276-288 (2007).

38. de Mattos e Silva, E. et al. Outcome of severe hypospadias repair using three different techniques. J. Pediatr. Urol. 5, 205-211 (2009).

39. Morera, A. M. et al. Is hypospadias due to metalloproteinase overactivity? Presented at the European Society for Paediatric Urology (ESPU) 2004 meeting.

40. Cook, A. et al. A multicenter evaluation of technical preferences for primary hypospadias repair. J. Urol. 174, 2354-2357 (2005).

41. Springer, A., Krois, W. \& Horcher, E. Trends in hypospadias surgery: results of a worldwide survey. Eur. Urol. 60, 1184-1189 (2011)

42. Koyle, M. A. Hypospadias: a 30-year personal journey. Scand. J. Surg. 100, 250-255 (2011).

43. Castagnetti, M., Zhapa, E. \& Rigamonti, W. Primary severe hypospadias: comparison of reoperation rates and parental perception of urinary symptoms and cosmetic outcomes among 4 repairs. J. Urol. 189, 1508-1513 (2013).

44. Vallasciani, S., Berrettini, A., Manzoni, G. \& Marrocco, G. Observational retrospective study on acquired megalourethra after primary proximal hypospadias repair and its recurrence after tapering. J. Pediatr. Urol. 9, 364-367 (2013).

45. Chrzan, R., Dik, P., Klijn, A. J. \& de Jong, T. P. Quality assessment of hypospadias repair with emphasis on techniques used and experience of pediatric urologic surgeons. Urology 70 , 148-152 (2007).

46. Marrocco, G., Calisti, A., Materia, E., Baglio, G. $\&$ Tancioni, V. The efficacy of surgical treatment of hypospadias: analysis of hospital data from Lazio region during the three year period (19961998). Pediatr. Med. Chir. 24, 223-227 (2002).

47. Chuang, J. H. \& Shieh, C. S. Two-layer versus one-layer closure in transverse island flap repair of posterior hypospadias. J. Pediatr. Surg. 30, 739-742 (1995).

48. Savanelli, A., Esposito, C. \& Settimi, A A prospective randomized comparative study on the use of ventral subcutaneous flap to prevent fistulas in the Snodgrass repair for distal hypospadias. World J. Urol. 25, 641-645 (2007).

49. Cimador, M., Pensabene, M., Sergio, M., Catalano, P. \& de Grazia, E. Coverage of urethroplasty in pediatric hypospadias: randomized comparison between different flaps. Int. J. Urol. http://dx.doi.org/10.1111/ iju.12092.

50. Gipson, M. Hypospadias repair using polyglycolic acid sutures. Br. J. Plast. Surg. 28, 135-138 (1975).

51. Bartone, F., Shore, N., Newland, J., King, L. \& DuPlessis, D. The best suture for hypospadias? Urology 29, 517-522 (1987).
52. Cimador, M. et al. Suture materials: do they affect fistula and stricture rates in flap urethroplasties? Urol. Int. 73, 320-324 (2004).

53. Guarino, N., Vallasciani, S. A. \& Marrocco, G. A new suture material for hypospadias surgery: a comparative study. J. Urol. 181, 1318-1323 (2009).

54. Grobbelaar, A. O., Laing, J. H., Harrison, D. H. \& Sanders, R. Hypospadias repair: the influence of postoperative care and a patient factor on surgical morbidity. Ann. Plast. Surg. 37, 612-617 (1996).

55. Chuang, J. H. \& Shieh, C. S. Two-layer versus one-layer closure in transverse island flap repair of posterior hypospadias. J. Pediatr. Surg. 30, 739-742 (1995).

56. Ben Meir, D. \& Livne, P. M. Is prophylactic antimicrobial treatment necessary after hypospadias repair? J. Urol. 171, 2621-2622 (2004).

57. McLorie, G. et al. Prospective randomized clinical trial to evaluate methods of postoperative care of hypospadias. J. Urol. 165, 1669-1672 (2001).

58. Van Savage, J. G., Palanca, L. G. \& Slaughenhoupt, B. L. A prospective randomized trial of dressings versus no dressings for hypospadias repair. J. Urol. 164, 981-983 (2000).

59. Braga, L. H., Lorenzo, A. J., Suoub, M. \& Bägli, D. J. Is statistical significance sufficient? Importance of interaction and confounding in hypospadias analysis. J. Urol. 184, 2510-2515 (2010)

60. Perovic, S. et al. Surgical challenge in patients who underwent failed hypospadias repair: is it time to change? Urol. Int. 85, 427-435 (2010).

61. Horton, C. E. \& Devine, C. J. A one-stage repair for hypospadias cripples. Plast. Reconstr. Surg. 45, 425-430 (1970).

62. Taylor, J. R., Lockwood, A. P. \& Taylor, A. J. The prepuce: specialized mucosa of the penis and its loss to circumcision. Br. J. Urol. 77, 291-295 (1996).

63. Winkelmann, R. K. The erogenous zones: their nerve supply and its significance. Proc. Staff Meet Mayo Clin. 34, 39-47 (1959).

64. Cold, C. J. \& Taylor, J. R. The prepuce. BJU Int. 83 (Suppl. 1), 34-44 (1999).

65. Leclair, M. D., Benyoucef, N. \& Héloury, Y. [Morbidity of foreskin reconstruction in distal hypospadias repair surgery]. Prog. Urol. 18, 475-479 (2008)

66. Cimador, M., Castagnetti, M. \& De Grazia, E. Risks and relevance of preputial reconstruction in hypospadia repair. Pediatr. Med. Chir. 25, 269-272 (2003).

67. Castagnetti, M., Cimador, M. \& De Grazia, E. Re: reconstruction of the hypospadiac hooded prepuce. J. Urol. 171, 2385 (2004).

68. Castagnetti, M. Commentary to 'Foreskin retractility following hypospadias repair with preputioplasty-Medium term outcomes'. J. Pediatr. Urol. http://dx.doi.org/10.1016/ j.jpurol.2013.03.019.

69. Snodgrass, W., Cost, N., Nakonezny, P. A. \& Bush, N. Analysis of risk factors for glans dehiscence after tubularized incised plate hypospadias repair. J. Urol. 185, 1845-1851 (2011).

70. Zaontz, M. R. \& Dean, G. E. Glandular hypospadias repair. Urol. Clin. North Am. 29 , 291-298 (2002)

71. Emir, L. \& Erol, D. Mathieu urethroplasty as a salvage procedure: 20-year experience. J. Urol. 169, 2325-2326 (2003)

72. Muruganandham, K. et al. Urethrocutaneous fistula after hypospadias repair: outcome of three types of closure techniques. Pediatr. Surg. Int. 26, 305-308 (2010). 
73. Elbakry, A. Management of urethrocutaneous fistula after hypospadias repair: 10 years' experience. BJU Int. 88, 590-595 (2001).

74. Cimador, M., Castagnetti, M. \& De Grazia, E. Urethrocutaneous fistula repair after hypospadias surgery. BJU Int. 92, 621-623 (2003).

75. Karamürsel, S. \& Celebioğlu, S. Urethral advancement for recurrent distal hypospadias fistula treatment. Ann. Plast. Surg. 56, 423-426 (2006).

76. Snodgrass, W. T., Bush, N. \& Cost, N. Algorithm for comprehensive approach to hypospadias reoperation using 3 techniques. J. Urol. 182 2885-2891 (2009).

77. Eliçevik, M., Tireli, G., Demirali, O., Unal, M. \& Sander, S. Tubularized incised plate urethroplasty for hypospadias reoperations in 100 patients. Int. Urol. Nephrol. 39, 823-827 (2007).

78. Jayanthi, V. R. et al. Can previously relocated penile skin be successfully used for salvage hypospadias repair? J. Urol. 152, 740-743 (1994).

79. Snodgrass, W. \& Elmore, J. Initial experience with staged buccal graft (Bracka) hypospadias reoperations. J. Urol. 172, 1720-1724 (2004).

80. Castagnetti, M. \& Rigamonti, W. Aptness and complications of labial mucosa grafts for the repair of anterior urethral defects in children and adults: single centre experience with 115 cases. World J. Urol. 27, 799-803 (2009).

81. Leslie, B. et al. Critical outcome analysis of staged buccal mucosa graft urethroplasty for prior failed hypospadias repair in children. J. Urol. 185, 1077-1082 (2011).

82. Nitkunan, T., Johal, N., O'Malley, K. \& Cuckow, P. Secondary hypospadias repair in two stages. J. Pediatr. Urol. 2, 559-563 (2006).

83. Simonato, A. et al. Lingual mucosal graft urethroplasty for anterior urethral reconstruction. Eur. Urol. 54, 79-85 (2008)

84. Castagnetti, M., Ghirardo, V., Capizzi, A., Andretta, M. \& Rigamonti, W. Donor site outcome after oral mucosa harvest for urethroplasty in children and adults. J. Urol. 180, 2624-2628 (2008).

85. Maarouf, A. M. et al. Buccal versus lingual mucosal graft urethroplasty for complex hypospadias repair. J. Pediatr. Urol. http:// dx.doi.org/10.1016/j.jpurol.2012.08.013.
86. Haxhirexha, K. N., Castagnetti, M., Rigamonti, W. \& Manzoni, G. A. Two-stage repair in hypospadias. Indian J. Urol. 24, 226-232 (2008).

87. Lorenzo, A. J. \& Snodgrass, W. T. Regular dilatation is unnecessary after tubularized incised-plate hypospadias repair. BJU Int. 89, 94-97 (2002).

88. Gargollo, P. C., Cai, A. W., Borer, J. G. \& Retik, A. B. Management of recurrent urethral strictures after hypospadias repair: is there a role for repeat dilation or endoscopic incision? J. Pediatr. Urol. 7, 34-38 (2011).

89. Lumen, N. et al. Etiology of urethral stricture disease in the 21st century. J. Urol. 182, 983-987 (2009).

90. Andersson, M., Doroszkiewicz, M., Arfwidsson, C. Abrahamsson, K. \& Holmdahl, G. Hypospadias repair with tubularized incised plate: does the obstructive flow pattern resolve spontaneously? J. Pediatr. Urol. 7, 441-445 (2011).

91. Husmann, D. A. \& Rathbun, S. R. Long-term followup of visual internal urethrotomy for management of short (less than $1 \mathrm{~cm}$ ) penile urethral strictures following hypospadias repair. J. Urol. 176, 1738-1741 (2006).

92. Scherz, H. C., Kaplan, G. W., Packer, M. G. \& Brock, W. A. Post-hypospadias repair urethral strictures: a review of 30 cases. J. Urol. 140, 1253-1255 (1988).

93. Ferro, F., Vallasciani, S., Borsellino, A., Atzori, P. \& Martini, L. Snodgrass urethroplasty: grafting the incised plate-10 years later. J. Urol. 182, 1730-1734 (2009).

94. Djordjevic, M. L. et al. "Hanging” of the bucca mucosal graft for urethral stricture repair after failed hypospadias. J. Urol. 185, 2479-2482 (2011).

95. Meeks, J. J., Erickson, B. A. \& Gonzalez, C. M. Staged reconstruction of long segment urethral strictures in men with previous pediatric hypospadias repair. J. Urol. 181, 685-689 (2009).

96. Uemura, S., Hutson, J. M., Woodward, A. A., Kelly, J. H. \& Chow, C. W. Balanitis xerotica obliterans with urethral stricture after hypospadias repair. Pediatr. Surg. Int. 16, 144-145 (2000).

97. Mattioli, G. et al. Lichen sclerosus et atrophicus in children with phimosis and hypospadias. Pediatr. Surg. Int. 18, 273-275 (2002).
98. Depasquale, I., Park, A. J. \& Bracka, A. The treatment of balanitis xerotica obliterans. BJU Int 86, 459-465 (2000).

99. Kumar, M. V. \& Harris, D. L. Balanitis xerotica obliterans complicating hypospadias repair. Br. J. Plast. Surg. 52, 69-71 (1999).

100. Aigen, A. B., Khawand, N., Skoog, S. T. \& Belman, A. B. Acquired megalourethra: an uncommon complication of the transverse preputial island flap urethroplasty. J. Urol. 137 712-713 (1987).

101. Elbakry, A. Complications of the preputial island flap-tube urethroplasty. BJU Int. 84, 89-94 (1999).

102. Singh, I. \& Hemal, A. K. Recurrent urethral hairball and stone in a hypospadiac: management prevention. J. Endourol. 15, 645-647 (2001).

103. Crain, D. S., Miller, O. F., Smith, L. J., Roberts, J. L. \& Ross, E. V. Transcutaneous laser hair ablation for management of intraurethral hair after hypospadias repair: initial experience. J. Urol. 170, 1948-1949 (2003).

104. Cohen, S., Livne, P. M., Ad-El, D. \& Lapidoth, M. $\mathrm{CO} 2$ laser desiccation urethral hair postpenoscrotal hypospadias repair. J. Cosmet. Laser Ther. 9, 241-243 (2007).

105. Beiko, D., Pierre, S. A. \& Leonard, M. P. Urethroscopic holmium:YAG laser epilation of urethral diverticular hair follicles following hypospadias repair. J. Pediatr. Urol. 7, 231-232 (2011).

106. Hayashi, Y. et al. Management of urethral calculi associated with hairballs after urethroplasty for severe hypospadias. Int. J. Urol. 14, 161-163 (2007).

107. Mir, T., Simpson, R. L. \& Hanna, M. K. The use of tissue expanders for resurfacing of the penis for hypospadias cripples. Urology 78, 1424-1429 (2011).

108. Thompson, J. H., Zmaj, P., Cummings, J. M. \& Steinhardt, G. F. An approach for using full thickness skin grafts for complex penile surgeries in children. J. Urol. 175, 1869-1871 (2006).

\section{Author contributions}

M. Cimador wrote, edited, and discussed this Review with colleagues. S. Vallasciani and M. Castagnett researched data and contributed towards writing the article. In addition, M. Castagnetti made substantial contributions towards discussions of content. G. Manzoni, W. Rigamonti, and E. De Grazia reviewed and edited the manuscript prior to submission. 